\title{
REINCARNATION AND NON-REINCARNATION IN THE ACTING PERFORMANCE OF MONODRAMA
}

\section{Istanbul / Türkive}

\section{p. 39-49}

\section{Article Information}

Article Type: Research Article This article was checked by iThenticate No plagiarism detected

\section{Article History}

Received: 06/05/2021

Accepted: 18/05/2021 published: 01/06/2021

\begin{abstract}
:
The problem of tagged research (reincarnation and reincarnation) boils down to the representative performance of monodrama Ask (how present is the reincarnation and presentation style in the monodrama show?) while the importance of the research was reflected in the highlighting (the specificity of the performance of the actor in the monodramatic play as an ancient art, and what the performance of the actor in monodrama and his style between presentation and reincarnation. The current research aims to reveal the style of reincarnation and presentation in the representative performance of monodrama, and determines the research with monodrama presentations presented in Baghdad for the period (2015-2018) and the terms of research (Reincarnation, Monodrama) were identified, while the second chapter focused on two topics, the first of which was what monodrama is and its roots, while the second focused on the technique of performance in monodrama. The Researcher took the descriptive approach as a way to conduct her research after she got the research community consisting of (5) monodramatic performances through which the sample was randomly elected through the draw by the reality of a theatrical work (EAA Harema) and after analyzing the theatrical performance the results of the research appeared from the most prominent (the use of the two methods of performance, reincarnation in the character of the man or reincarnation in the simulation of other characters. The use of kinetic and vocal skill in presenting the character (officer) and others, reaching a sensory embodiment of the character of war is invisible, and making it felt by Receiver) The researcher concluded what comes (the actor who deals with the work of Monodrami must master the tragic and comedic performance and blend them. The researcher recommended the need to prepare special workshops to write, direct and represent monodrama.
\end{abstract}

Key words: Monodrama, Reincarnation, Non-Reincarnation.

http://dx.doi.org/10.47832/2791-9323.2-2.4

Dr. , Tikrit University, Iraq, Eman.a.atallah@tu.edu.iq, https://orcid.org/0000-0002-0682-8250 


\title{
التقمص واللاتقمص في الأداء التمثيلي للمونودراما \\ ايمان عبد الستار عطا الله الكبيسي 2
}

\begin{abstract}
الملخص

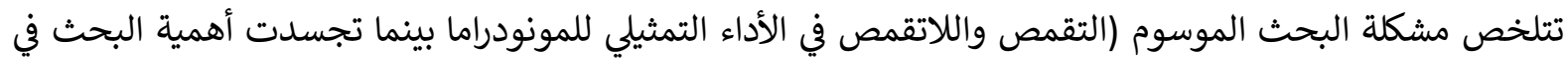

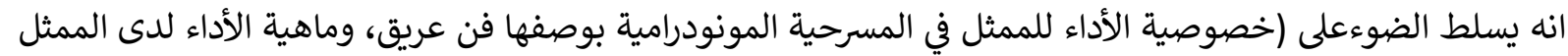

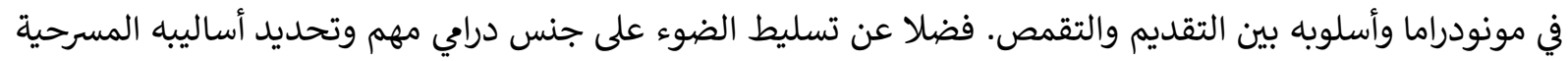

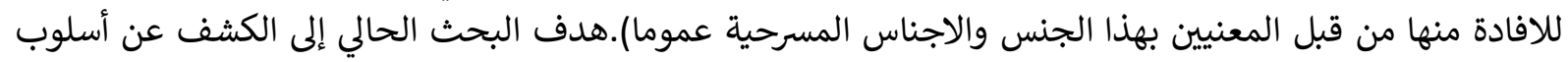

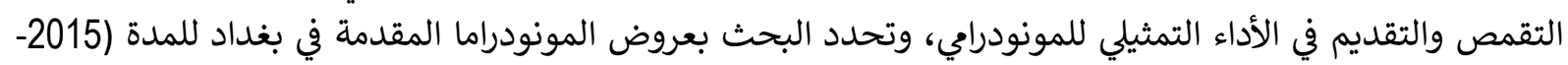

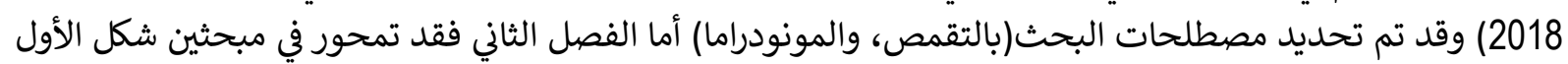

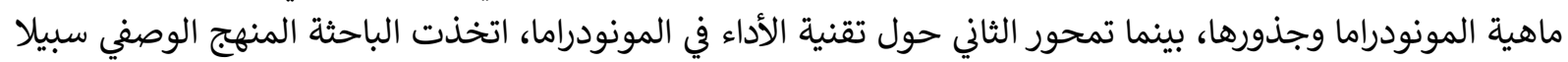

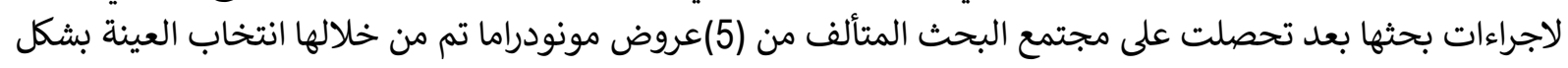

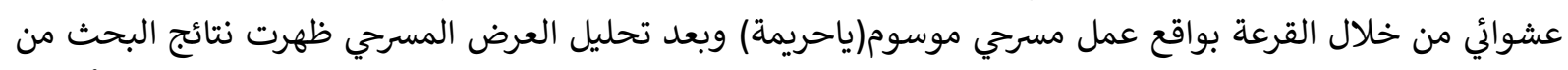

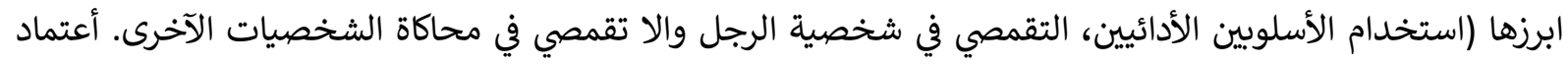

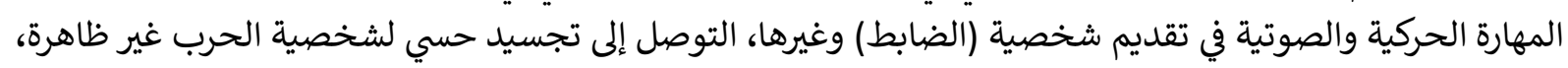

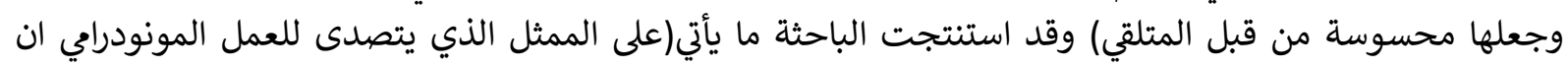

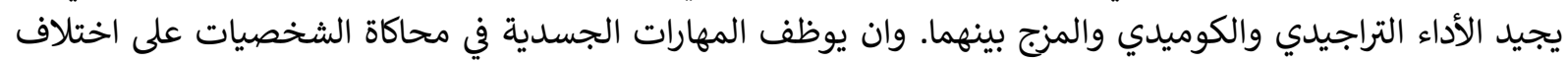

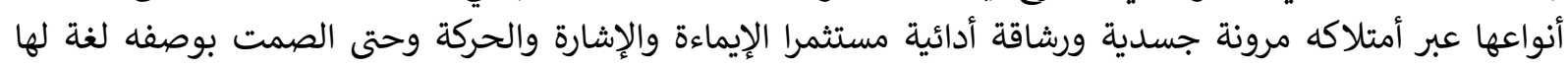

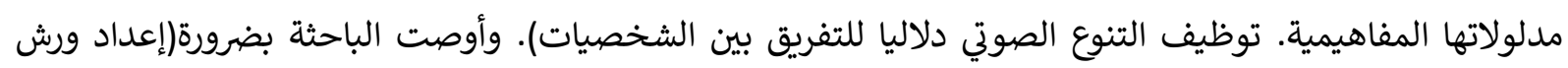

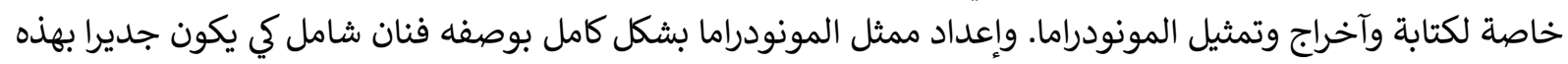

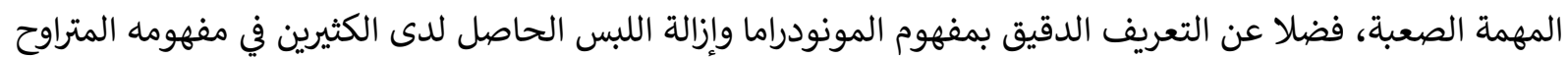

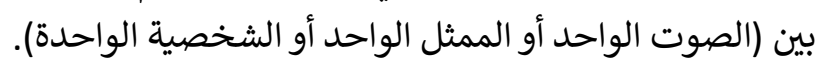
الكلمات المفتاحية: التقمص، اللاتقمص، النص، مونودراما.
\end{abstract}


مشكلة البحث: تمثلت مشكلة البحث بالتساؤل الآتي :

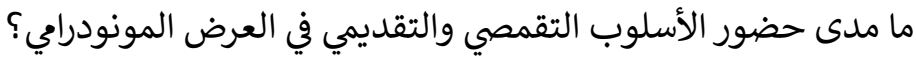

أهمية البحث: تأتي أهمية البحث الحالي من أنه يبحث في :

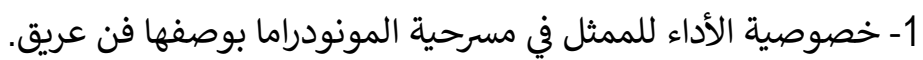

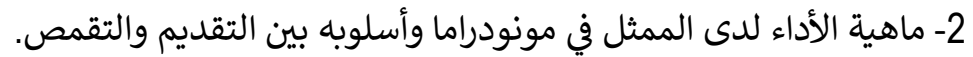

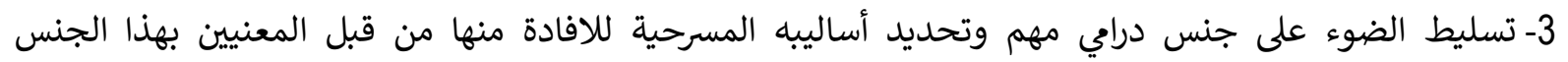
والاجناس المسرحية عموما.

هدف البحث: يهدف البحث الحالي إلى الكشف عن أسلوب التقمص والتقديم في الأداء التمثيلي للمونودرامي. حدود البحث: يتحدد البحث الحالي بعروض المونودراما المقدمة في بغداد للمدة (2014-2018)

يتمثل (بالانفعالات النفسية التي تحددها تغيرات عضوية لوصول الممثل إلى الانفعال الذي ينقله إلى المشاهد ويغريه

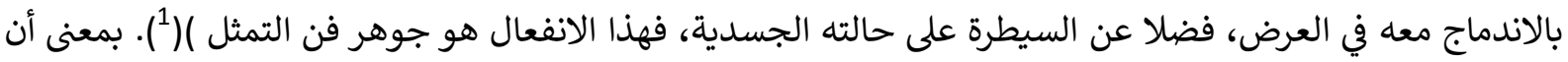

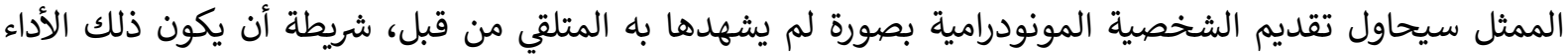

مقنعا للمشاهد ومريحا للممثل.

المونودراما

كلمة المونودراما( Mono drama)كلمة يونانية تُقسم إلى(Mono وتعني (وحيد)، و (Drama) وتعني (الفعل). وتعني

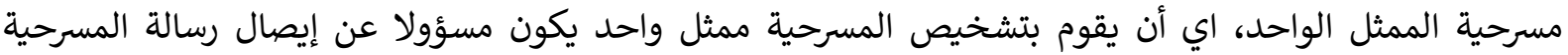

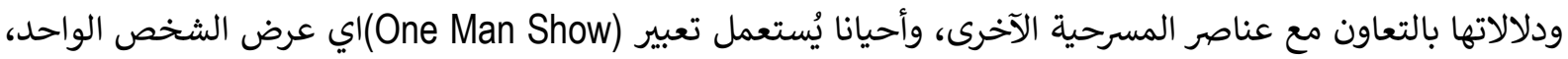

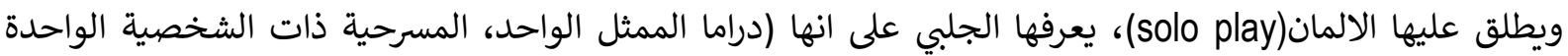

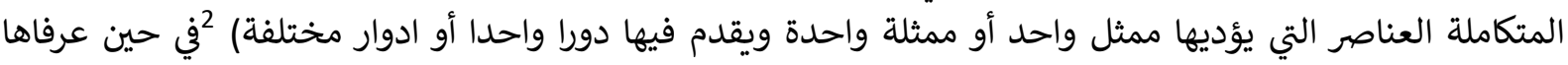

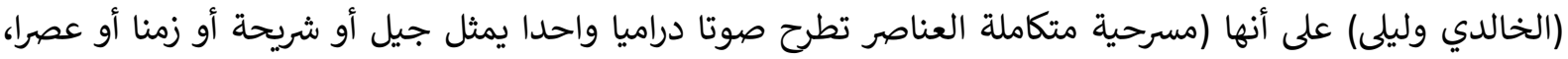

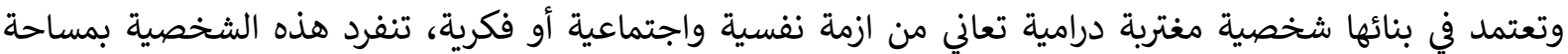

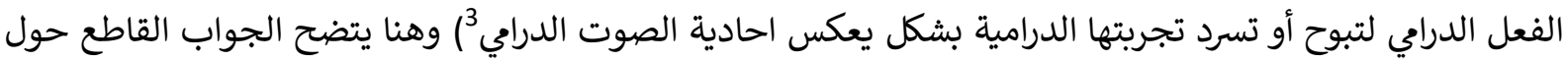

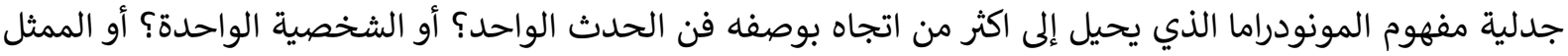

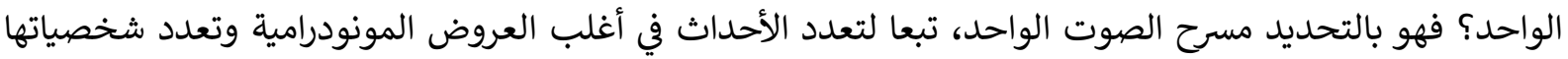

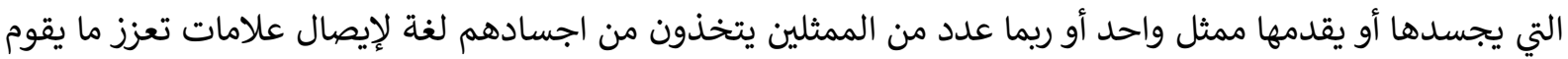

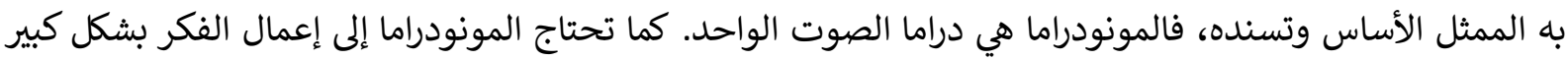

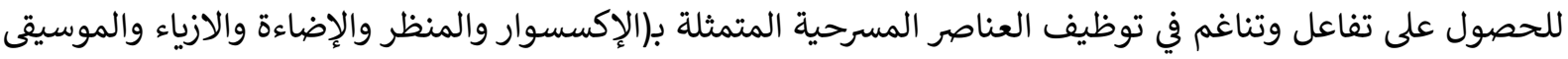

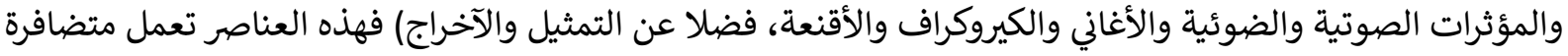

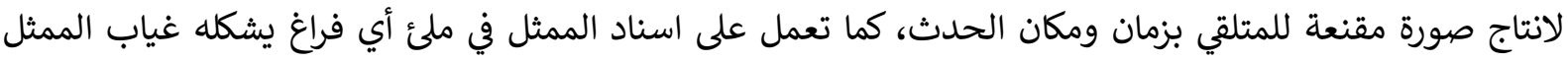
المقابل. 


\section{الفصل الثاني / المبحث الأول/ ماهية المونودراما وجذورها}

يرجع الكثيرون أصل المونودراما إلى ما قدمه الممثل والكاتب المسرحي الألماني (جوهان كريستيانابراندز)عام 1775-

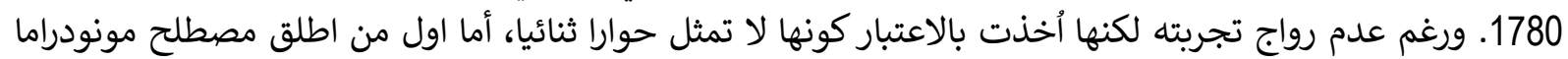

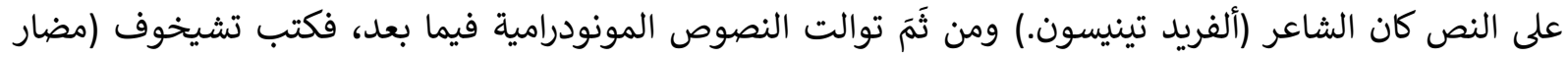

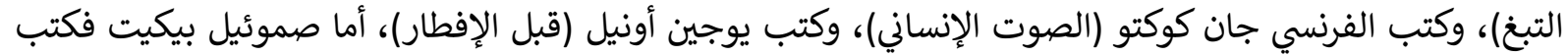

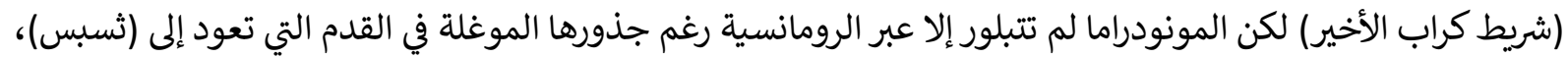

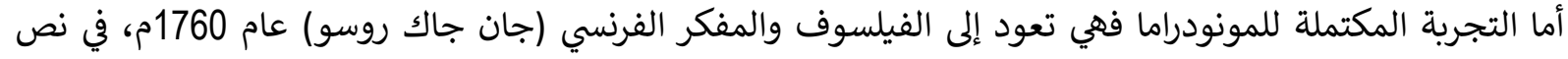

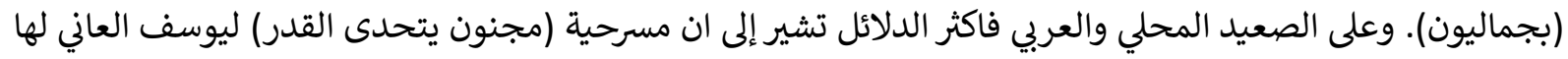

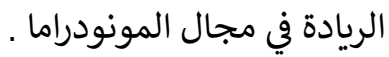

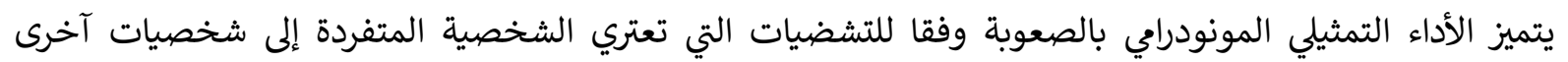

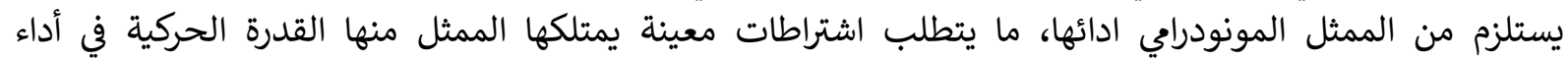

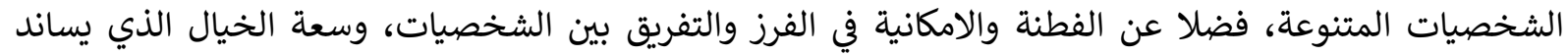

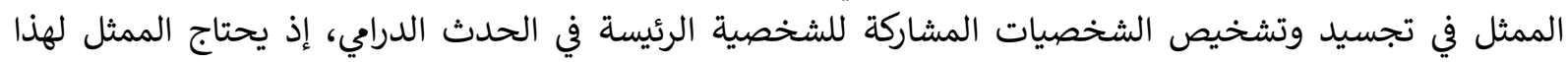

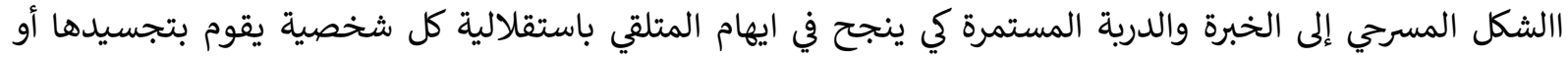

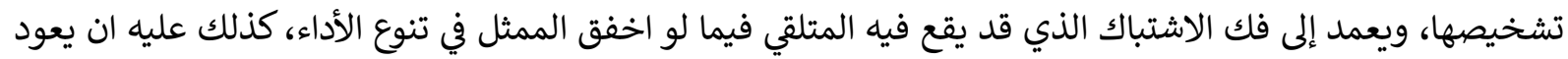

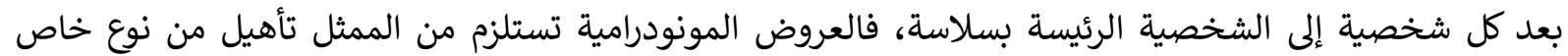

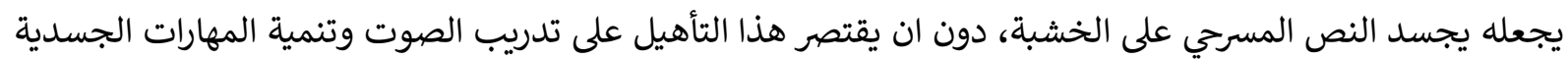

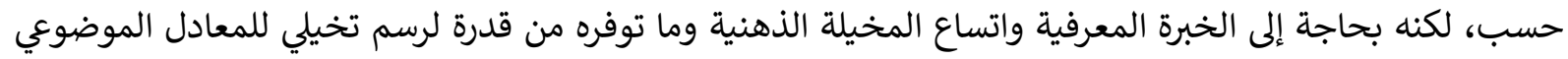

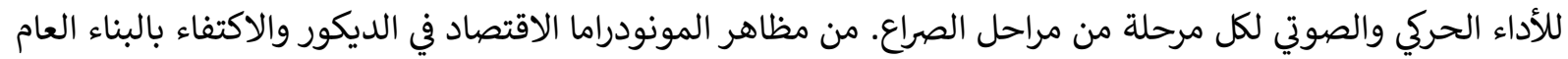

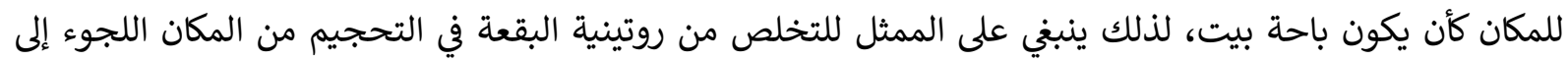

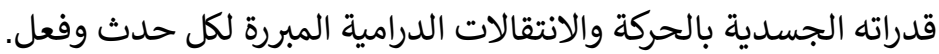

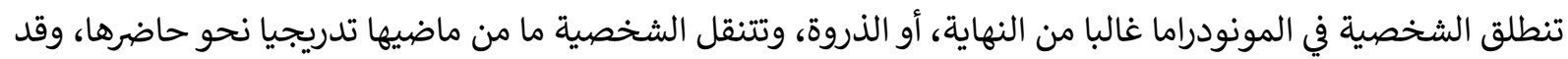

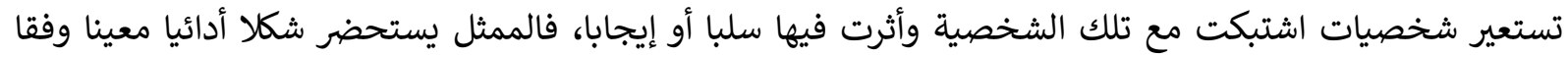

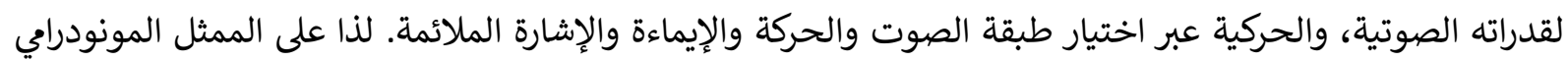

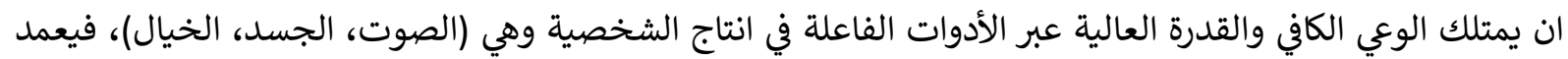

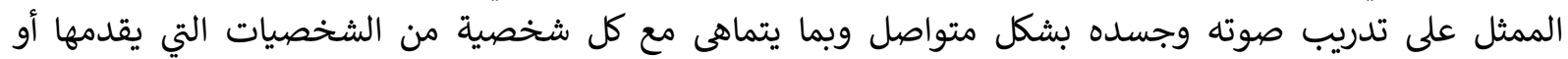

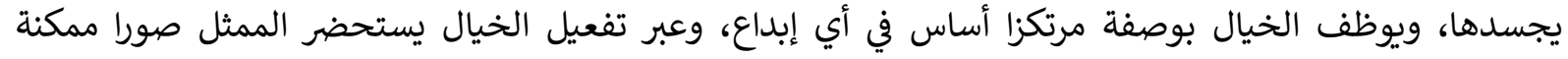
مجسدة عبر الجسد والصوت يساعده في ذلك الثقافة العالية والرصانة العلمية .

\section{المبحث الثاني /تقنية الأداء في المونودراما}

تتارجح التقنية المستخدمة في الأداء المونودرامي بين الأداء الكوميدي والتراجيدي في تباين مع المسرحيات التقليدية، إذ إذاء

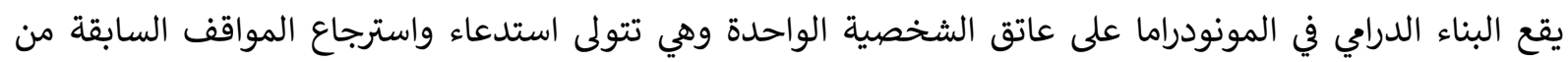

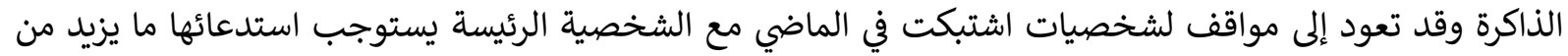

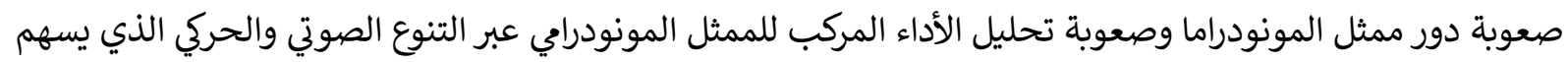

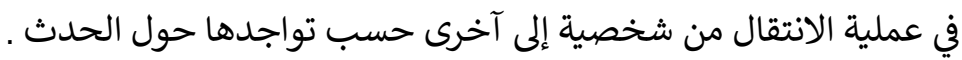

فالأداء المونودرامي يجمع بين تقنيات المناهج التمثيلية المتنوعة منها منهج المعايشة بتجسيد صفات التهات الشخصية

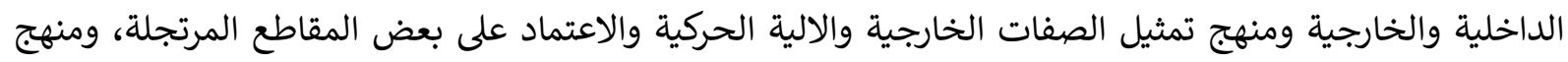

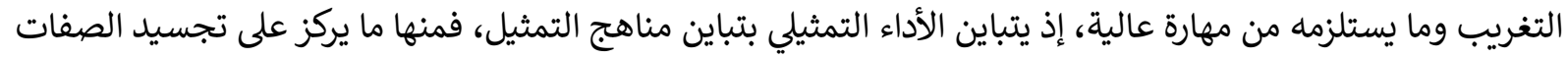
الداخلية الشعورية لتجسيد الصفات الخارجية للدور (فقد يتخذ الممثل من المنحى الخيالي التقمصي لأداء تلك 
لشخصية، وتبرز قدرة الممثل في اختياره أداءا صوتيا وحركيا غير مألوفا، بمعنى أن الممثل سيحاول تقديم الشخصية

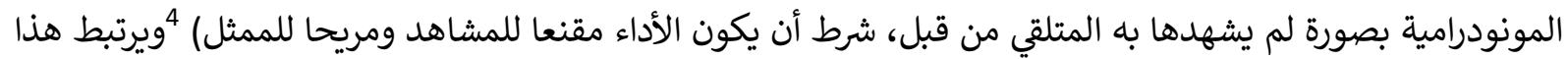

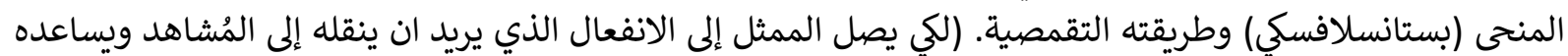

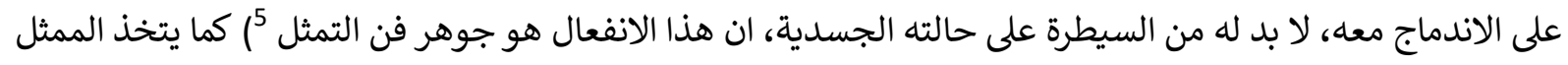

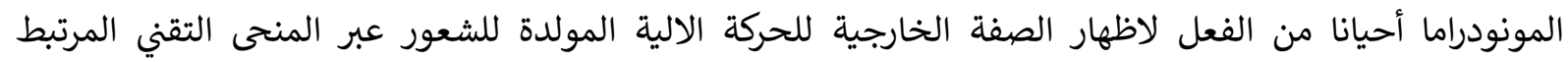

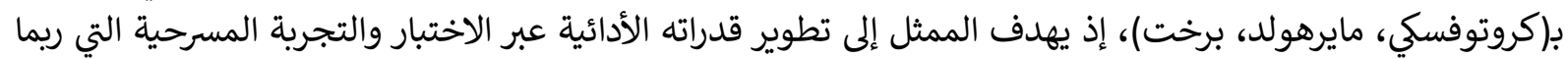

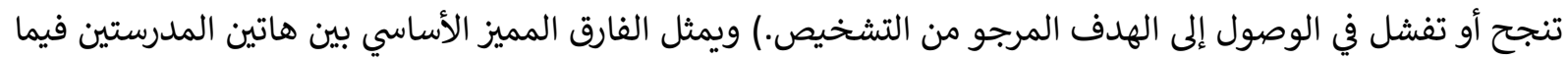

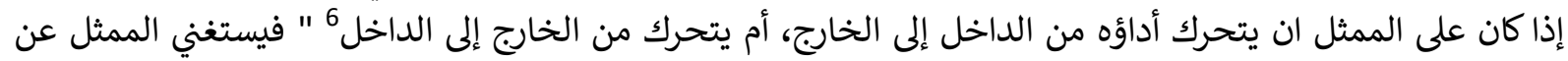

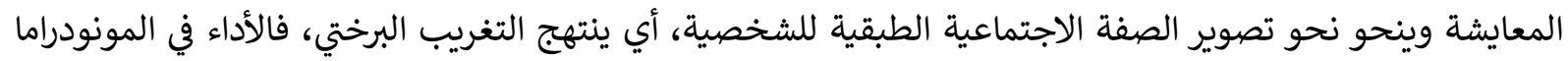

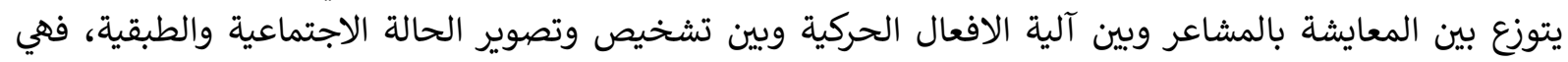

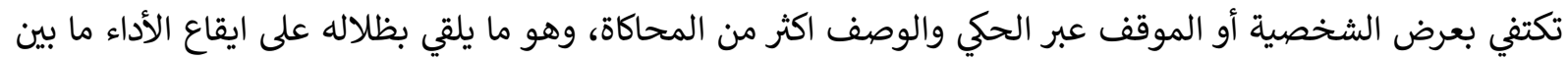

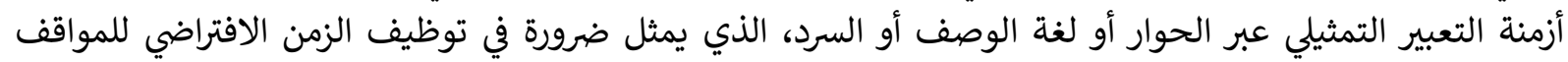
المستعارة من الذاكرة .

يتقمص الممثل في المسرحية التقليدية يتقمص دورا واحدا، أما في المونودراما فأن الممثل فأنه يؤدي دورا واحدا إندا وفقا

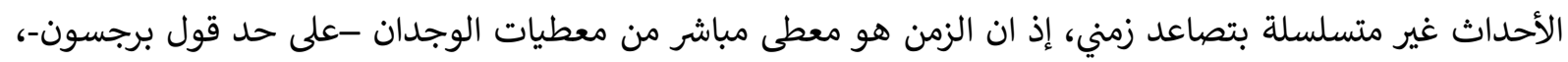

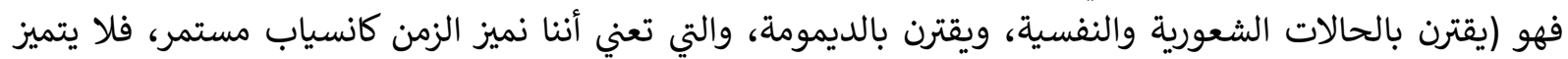

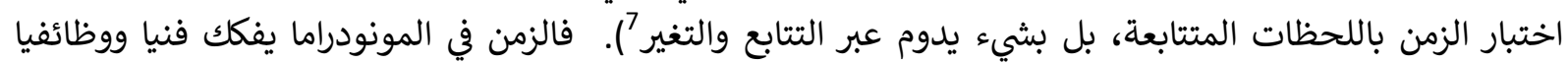

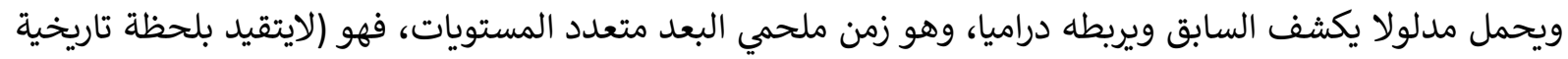

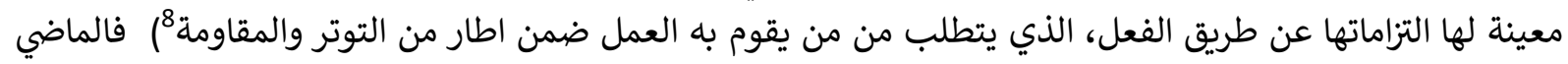

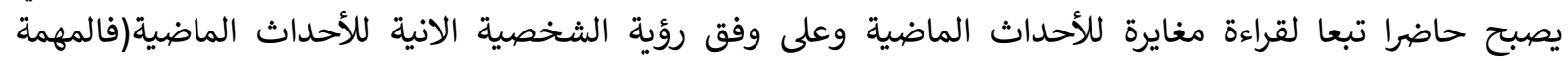

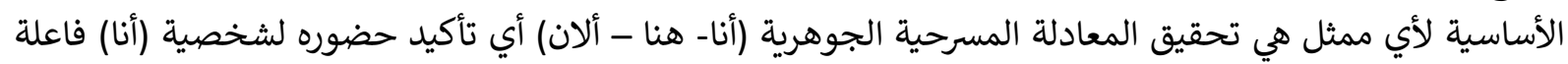

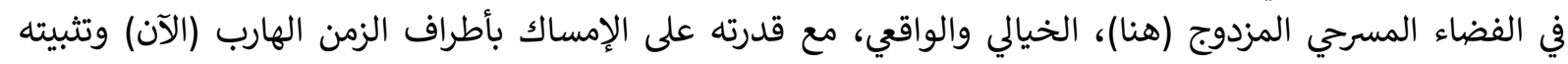

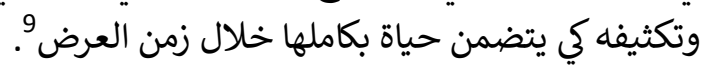

أغلب نصوص المونودراما تتخذ من تنوع الشخصيات مسلك لها، ما يضاعف جهد الممثل، ويشكل عقبة امامه في

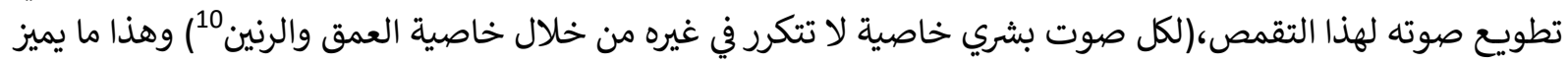

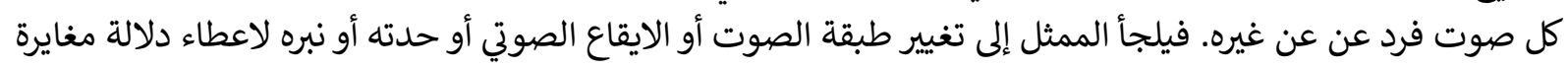

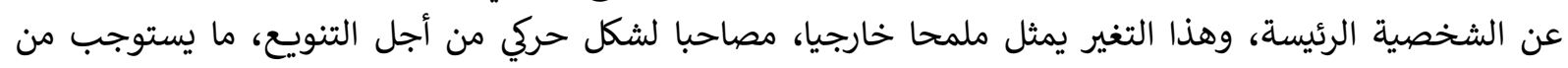

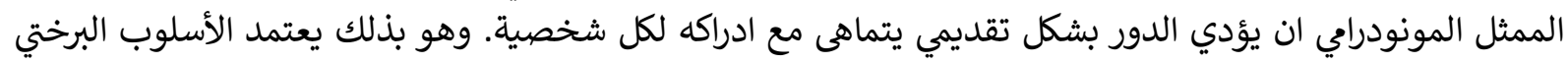

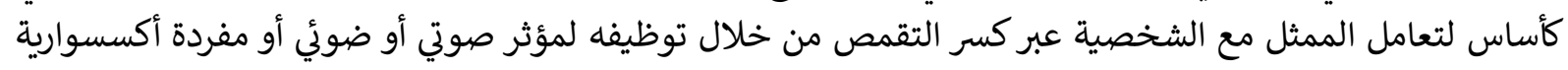
لد الدى الممثل والمتلقي معا.

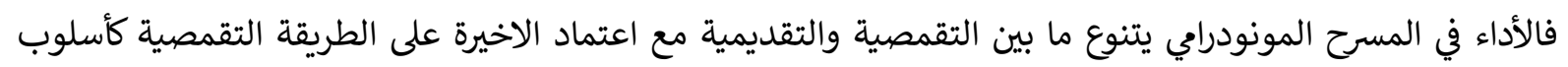

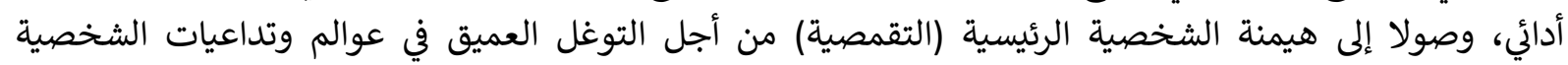

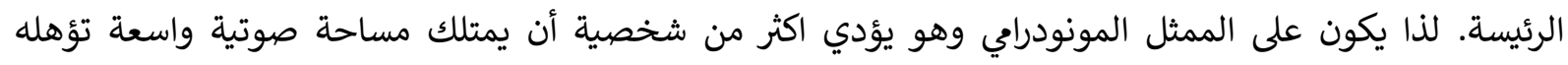

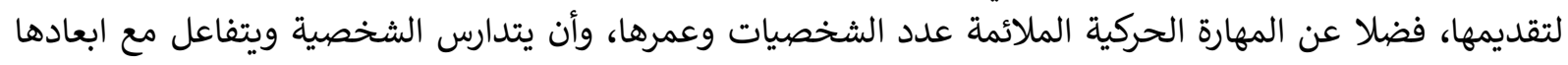

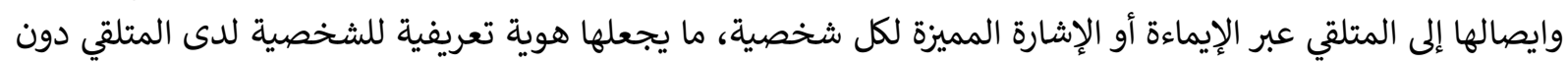

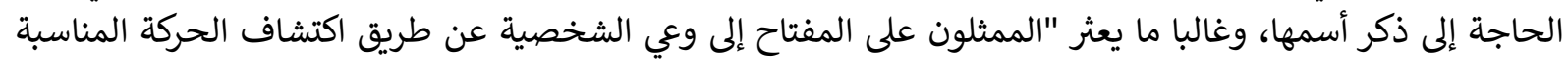

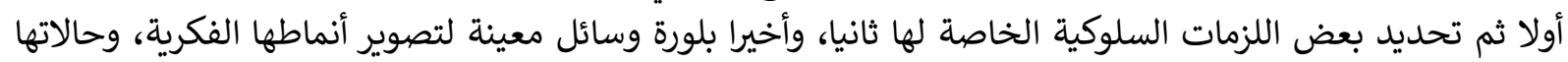

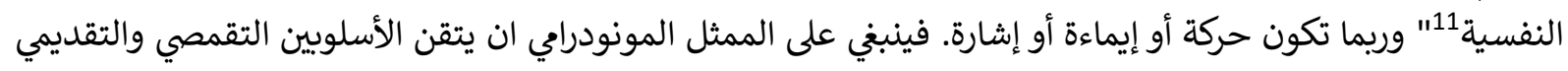

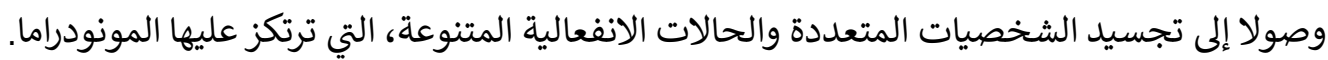


لعدم تراتبية الأحداث تتكون المونودراما غالبا من مشاهد منفصلة من حيث أداء الشخصية الرئيسة أو حتى الشخصيات

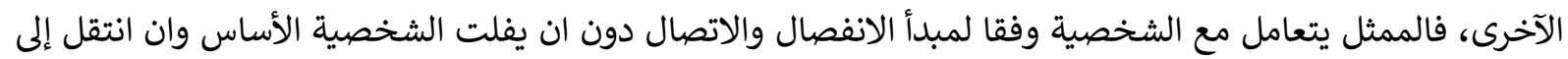

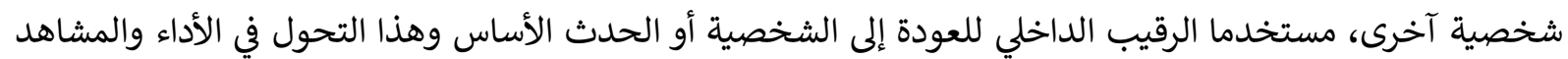

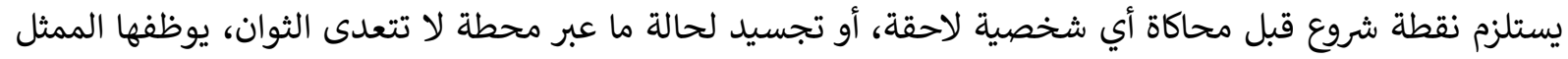

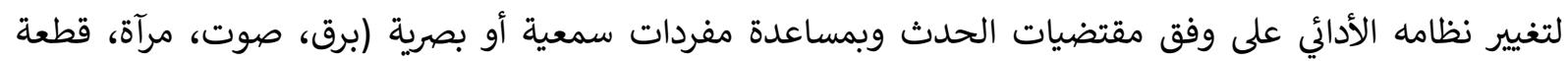

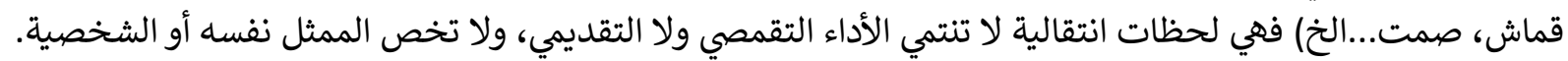

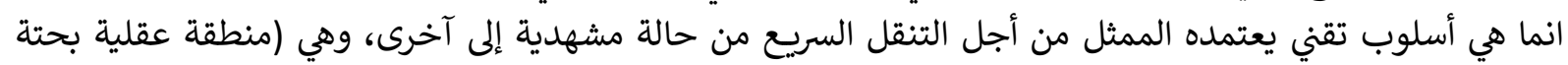

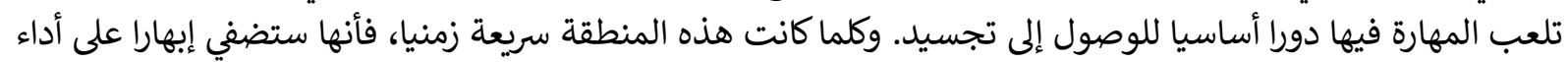

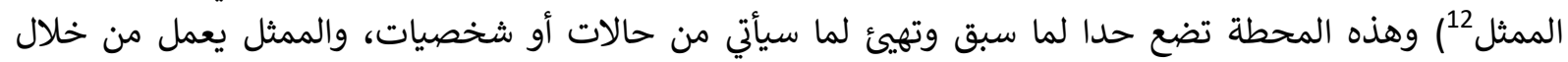

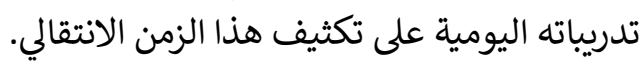

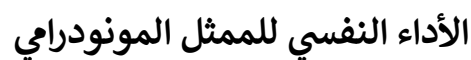

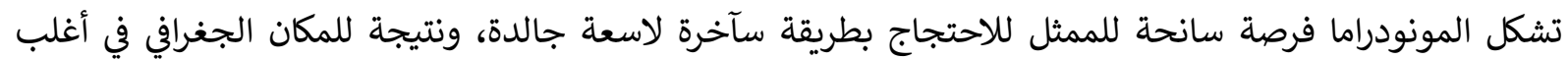

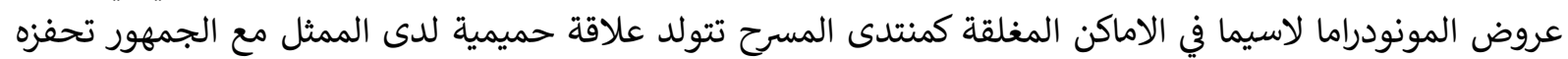

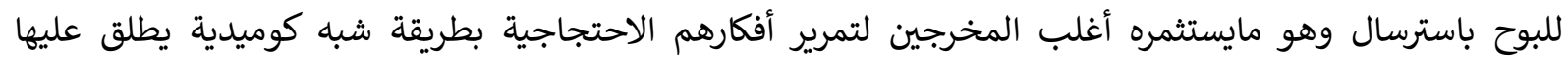

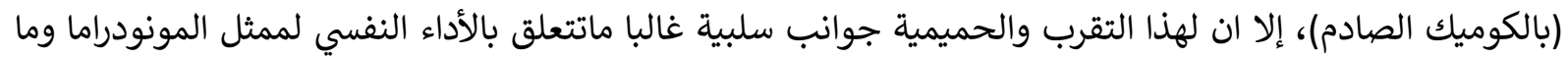

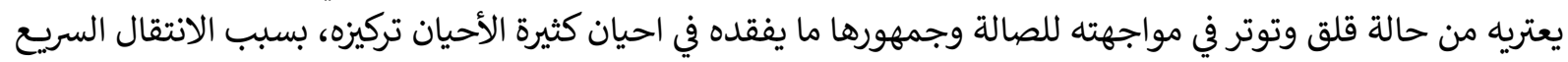

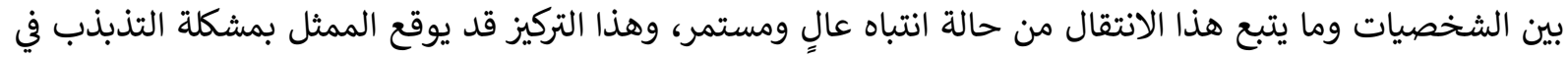

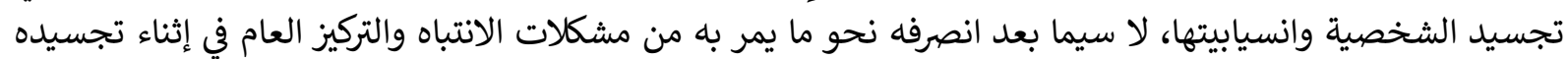

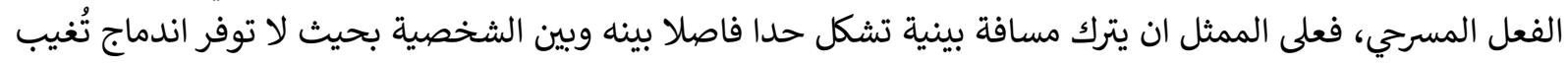

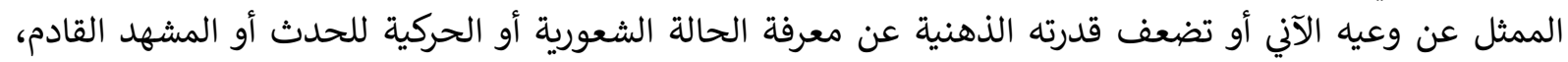

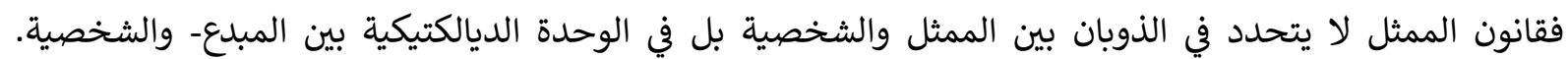

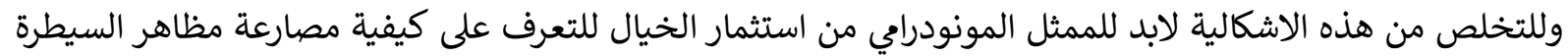

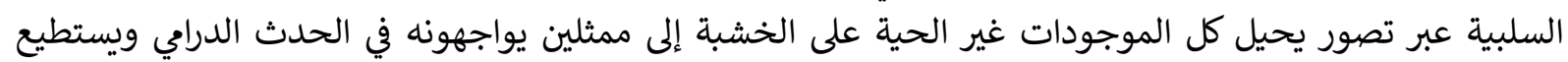

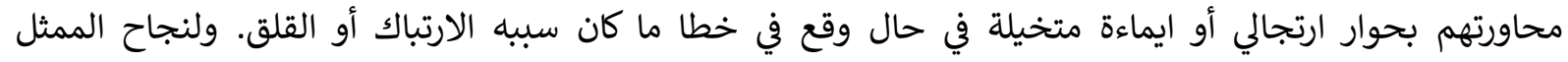

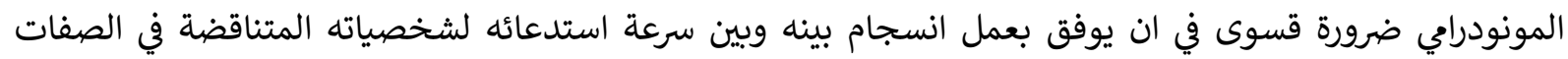

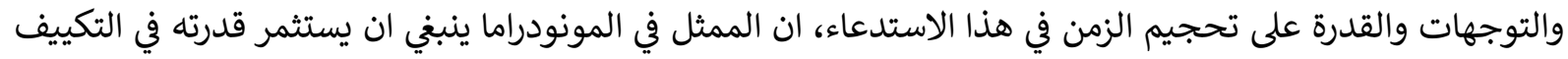

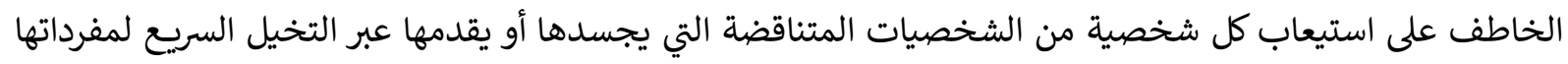

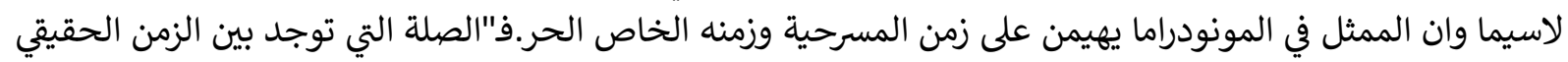

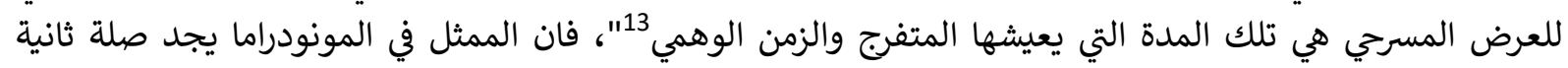

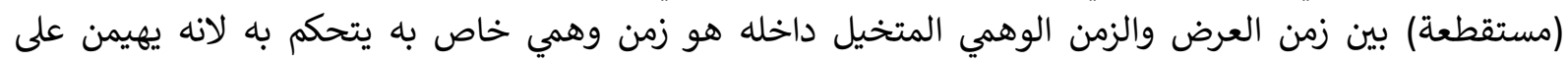
الموجودات على الخشبة وعناصر العرض. 
منهجية البحث: اتبعث الباحثة المنهج الوصفي التحليلي مجتمع البحث: يتألف مجتمع البحث من عروض المونودراما التي قدمت على مسارح بغداد، للمدة مابين (2015-

وقد توصلت الباحثة إلى المسرحيات الآتية: - المات

\begin{tabular}{|c|c|c|c|c|}
\hline تاريخ العرض & المخرج & المؤلف & عنوان المسرحية & ت \\
\hline 2015 & مناضل داود & مناضل داود & مخفر الشرطة القديم & 1 \\
\hline 2015 & علي العبادي & علي العبادي & |الحقائب السود & 2 \\
\hline 2017 & حسين علي هارف & حسين علي هارف & | يا حريمة & 3 \\
\hline 2018 & علي العبادي & علي العبادي & حذائي & 4 \\
\hline 2018 & ي هارف & حسين ع & باء الموت & 5 \\
\hline
\end{tabular}

عينة البحث: اختارت الباحثة العينة بشكل عشوائي من بين خمسة عروض شكلت مجتمع البحث وتمثلت بمسرحية (ياحريمة)

تحليل العرض

مسرحية (ياحريمة)

تأليف وآخراج: حسين علي هارف

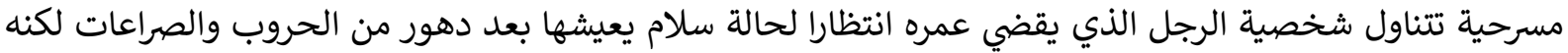

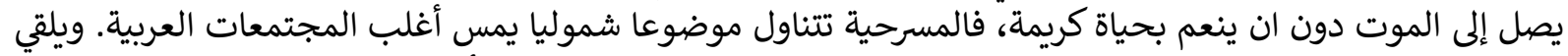

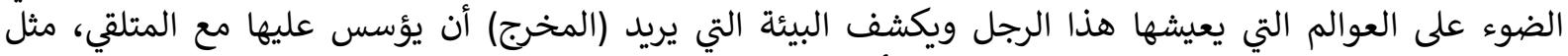

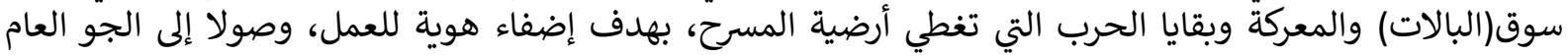

للمسرحية.

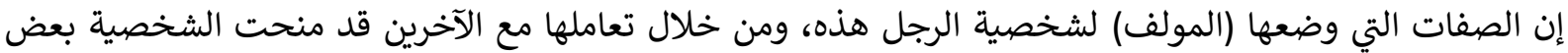

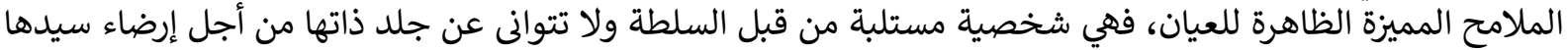

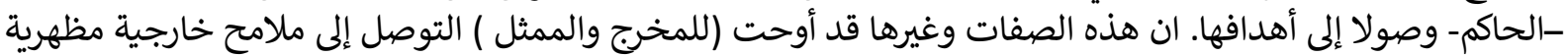

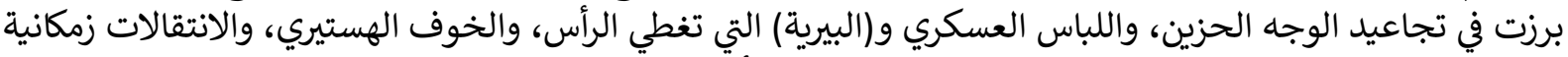

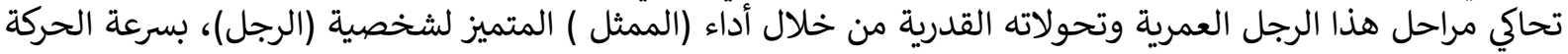

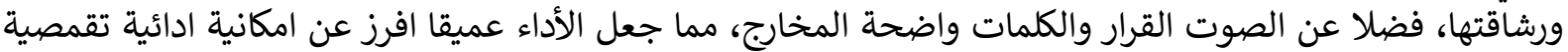

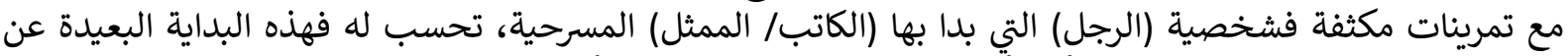

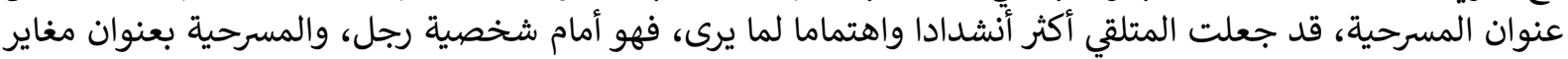
(يا حريمة ) التي تعد من روائع الفن ألغنائي العراقي.

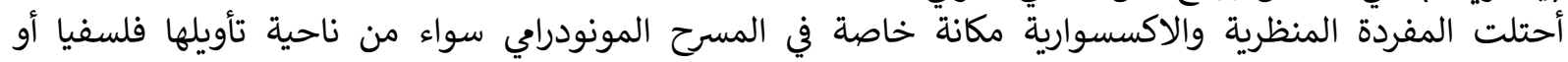

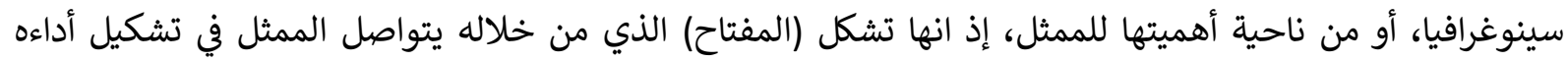

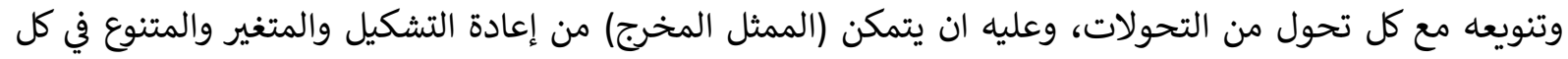

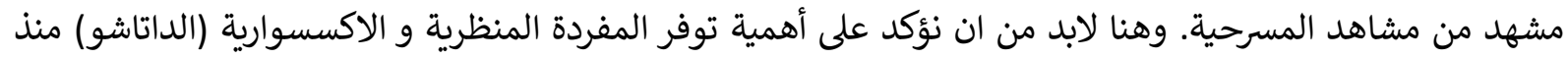


القراءة الأولى للمسرحية، وذلك من اجل التوصل إلى التوظيف المتنوع للمفردة وتسهيل عملية التعامل معها من قبل (الممثل)، وصولا إلى الأداء الأمثل.

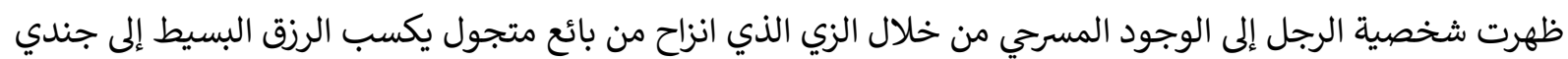

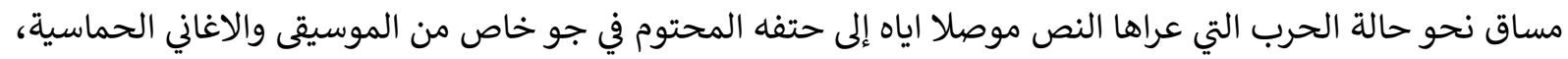

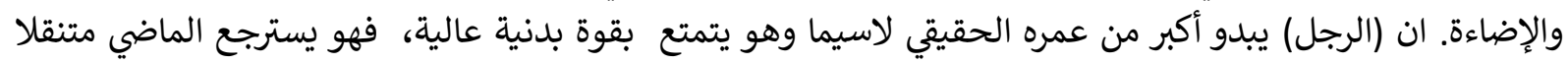

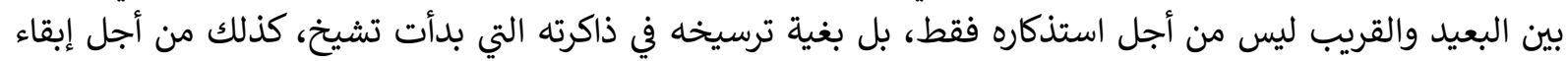

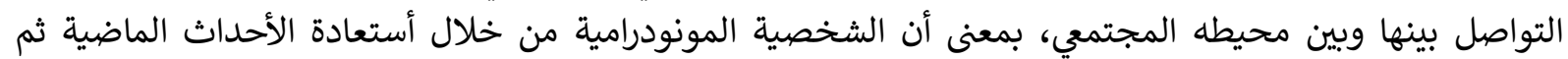

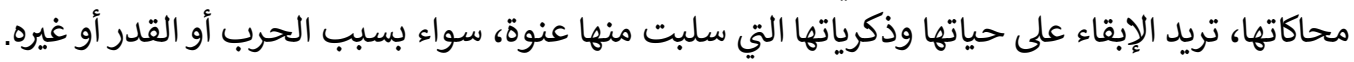

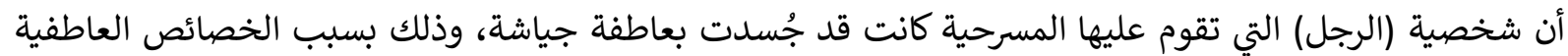

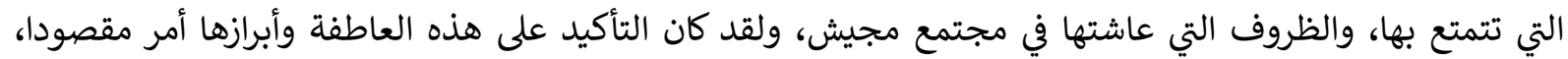

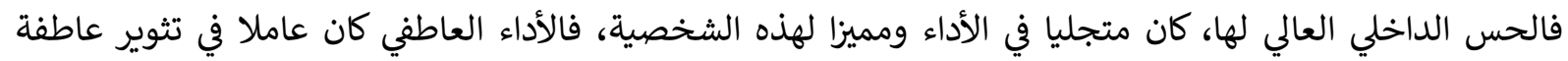

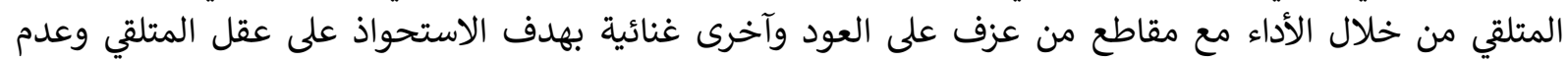

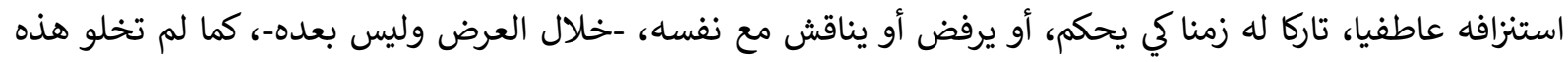

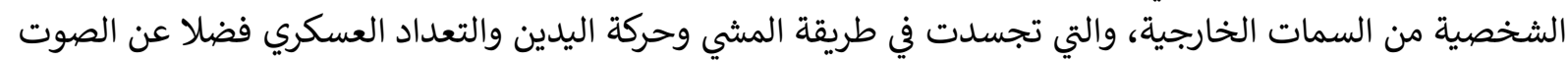

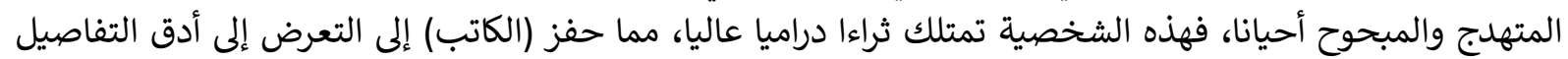

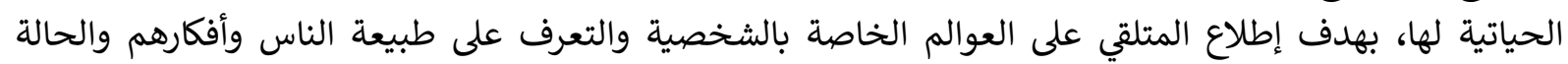

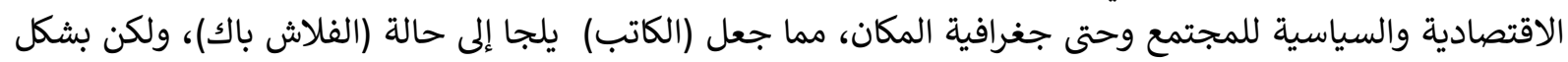

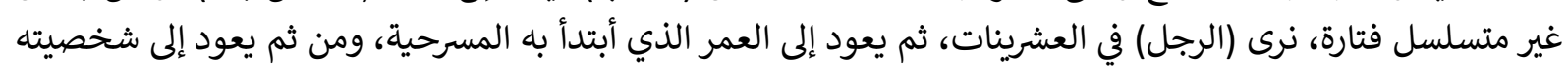

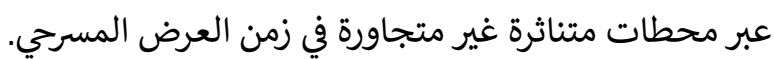

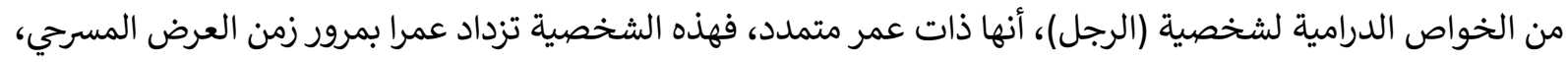

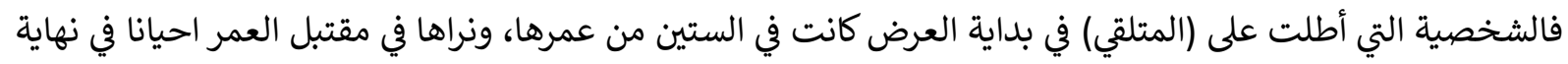

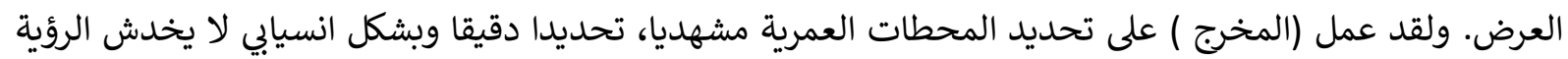

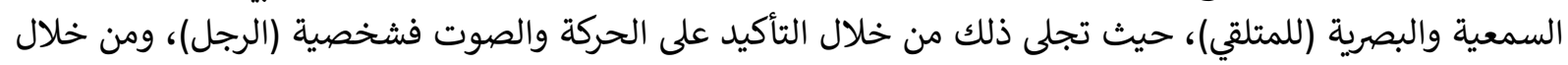

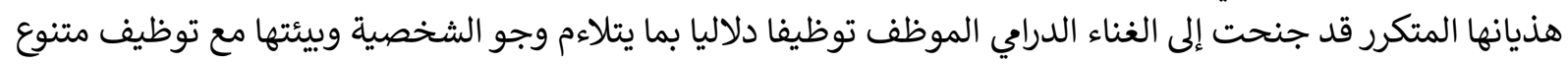

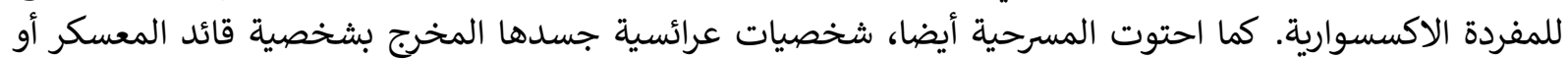

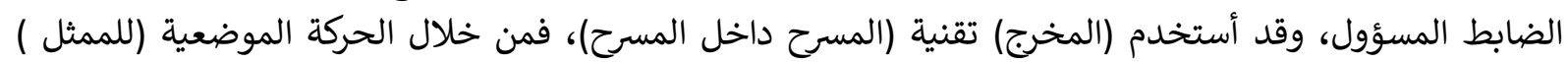

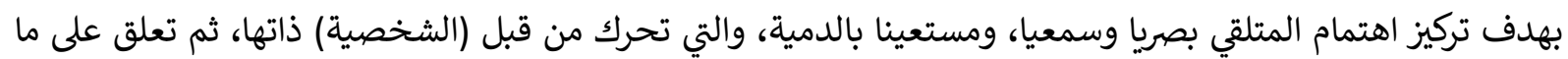

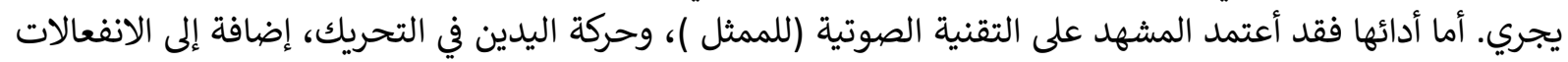

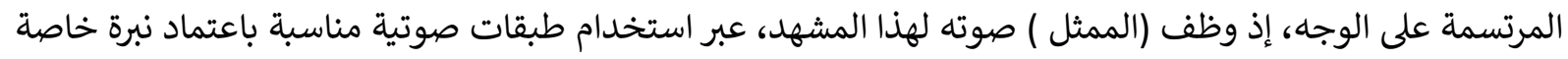

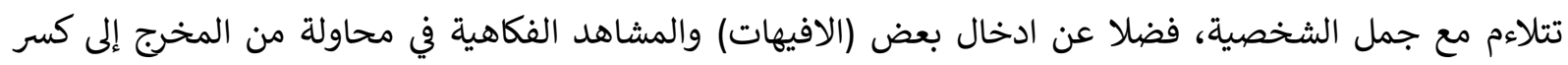
الطابع الحزين للمونودراما. اما الأداء المشهدي فقد توزع ما بين لئن الأداء العاطفي (التقمصي) والأداء التقني الخارجي صوتيا (اللاتقمصي) من خلال

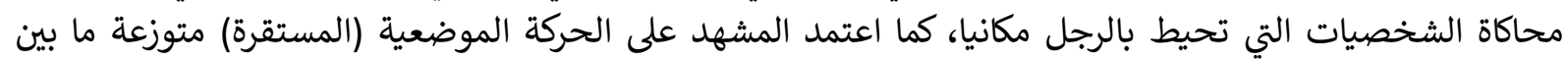

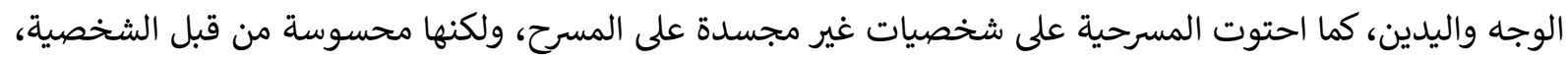

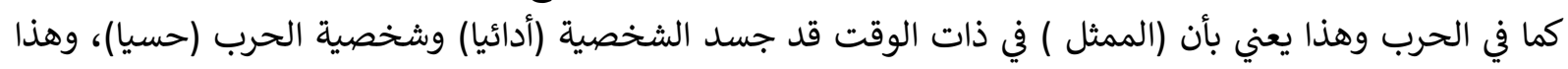

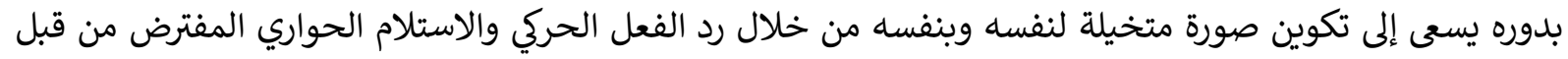

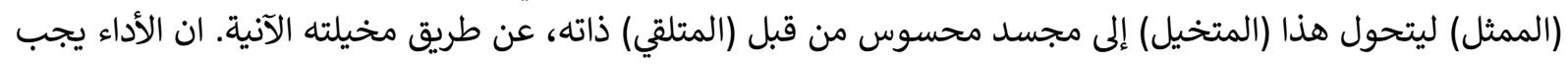

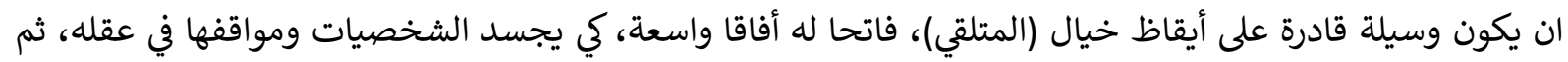

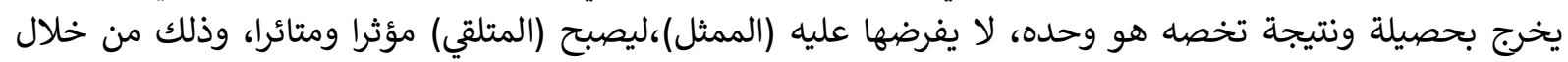

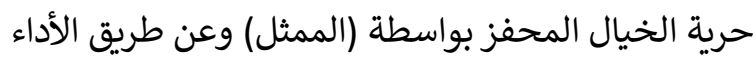


تؤكد (الباحثة)، ومن خلال تحليلها لمسرحية (ياحريمة) أهمية التقنية الصوتية للممثل في المسرحية المونودرامية، وعلى الماتل

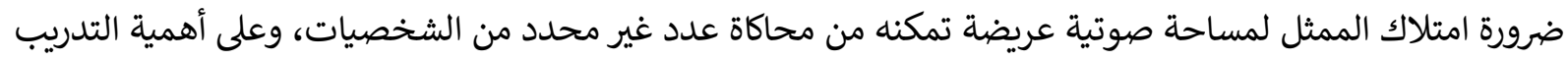

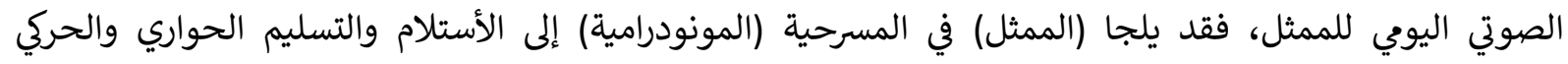

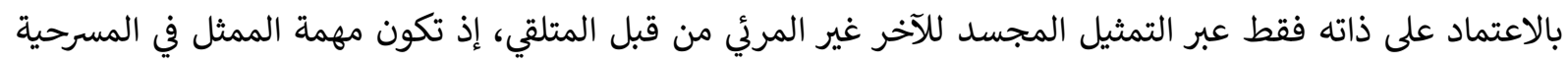

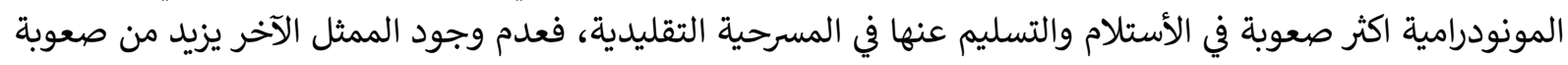

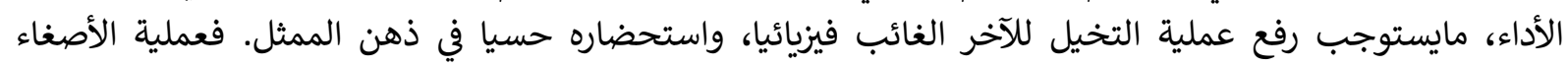

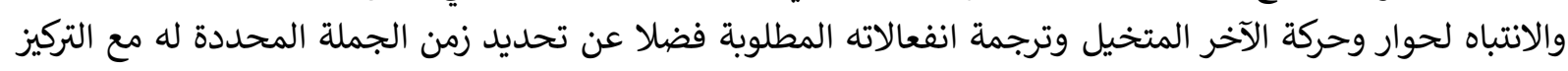

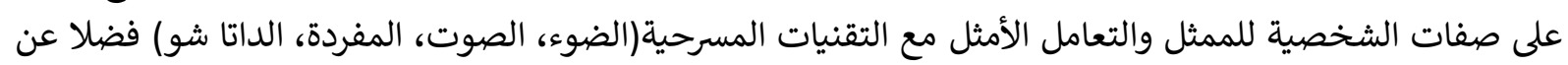

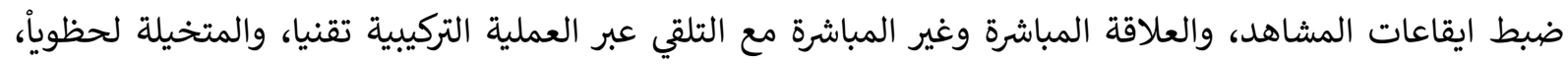

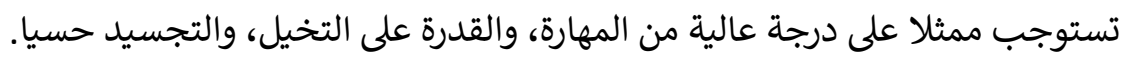


International Journal of Education and Language Studies

الفصل الرابع/النتائج والاستنتاجات

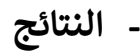

من تحليل الأداء في المسرحية، توصلت الباحثة إلى ما يأتي:

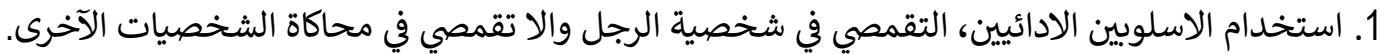

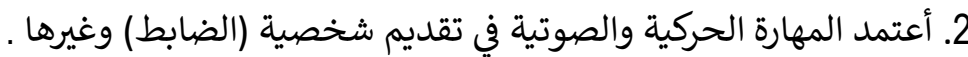

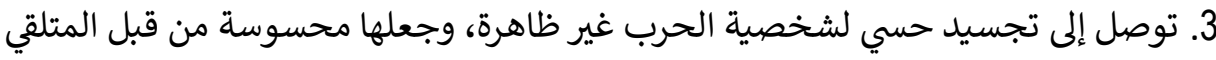

4. استخدمت الرقص والغناء، كمهارة أضافية ومكملة للشخصية تورية.

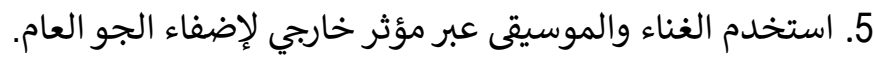

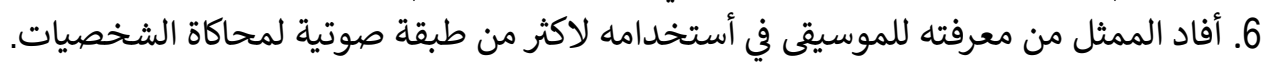

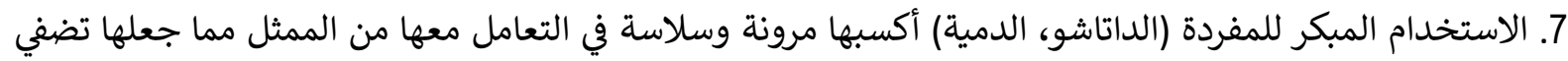

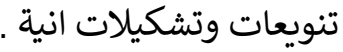

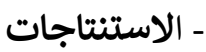

1.

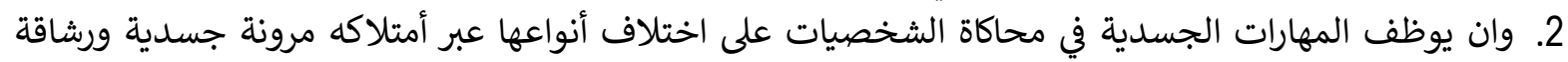

ادائية مستثمرا الإيماءة والإشارة والحركة وحتى الصمت بوصفه لغات لغة لهات لها مدلولاتها المفاهيمية .

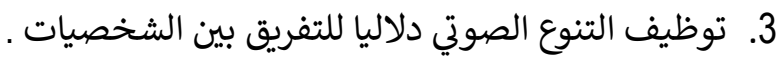

4. تعتمد المونودراما اسلوب كولاجي في تنوع وانتقائية تلزم الممثل بسياحة جمالية بين الروي والسرد والتقمص واللا

تقمص .

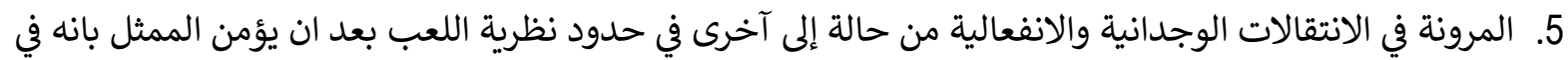

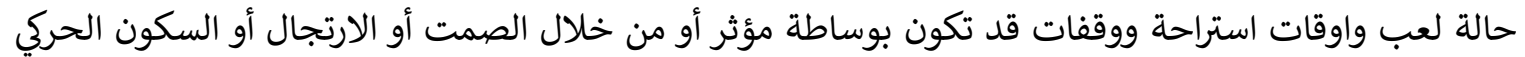

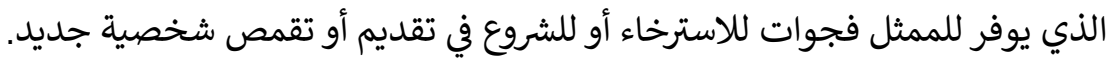

- التوصيات: توصي الباحثة

1. بضرورة اعداد ورش خاصة لكتابة وآخراج وتمثيل المونودراما.

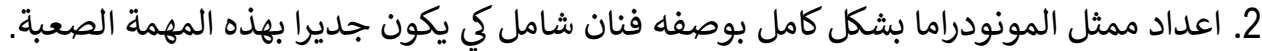

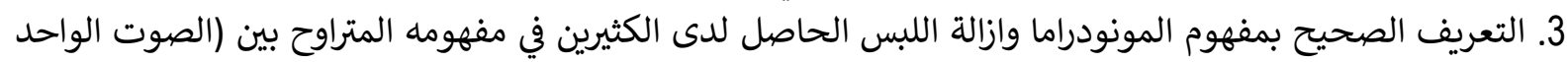

أو الممثل الواحد أو الشخصية الواحدة) 


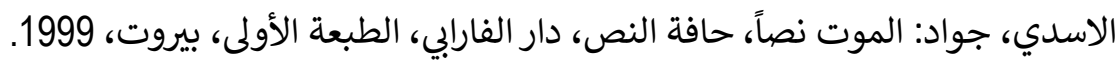

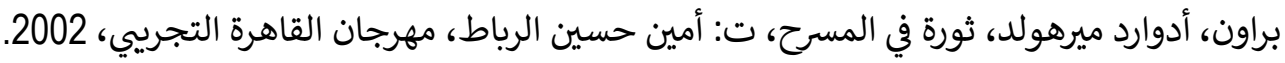

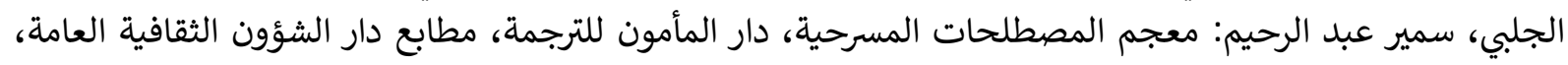
بغداد، 1993.

الخالدي، ميمون وليلى محمد: المونودراما في المسرح العراقي / دراسة الأداء لاول مسرحية مونودرامية عراقية، مجلة

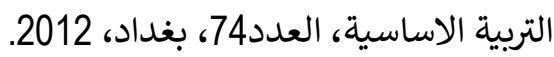

سعد، صالح: الانا/ الآخر،ازدواجية الفن التمثيلي، عالم المعرفة، المجلس الوطني للثقافة والفنون والاداب،الكويت، 2005

غاستون باشلار، جدلية الزمن،ت: خليل أحمد خليل، ديوان المطبوعات الجامعية، الجزائر، د.ت .

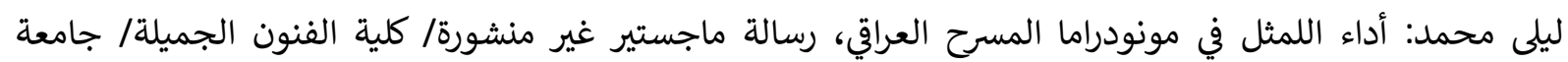

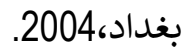

محمود ابو العباس: المونودراما- مسرحية الممثل الواحد، مكتبة العبيكان، الرياض،

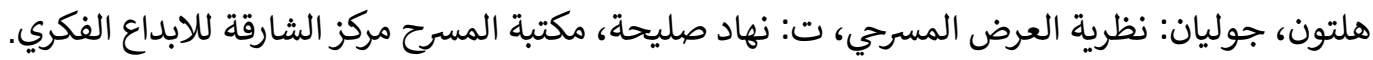

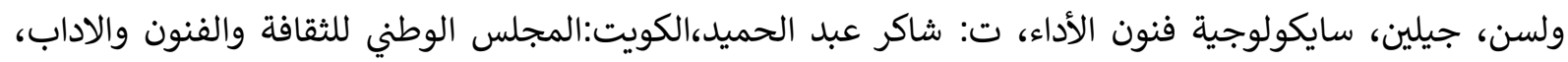
2000

\section{الهوامش}

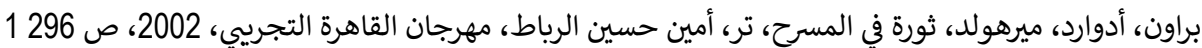

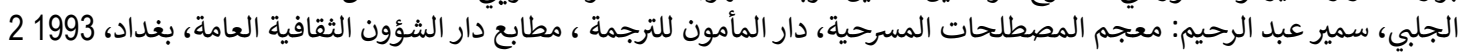
الخالدي، ميمون وليلى محمد: المونودراما في المسرح العراقي / دراسة الاداء لاول مسرحية مونودرامية عراقية العراقية، مجلة التربية الاساسية، العددادية،

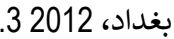
ليلى محمد: اداء اللمثل في مونودراما المسرح العراقي، رسالة ماجستير غير منشورة/ كلية الفنون الجميلة/ جامعة بغداد،

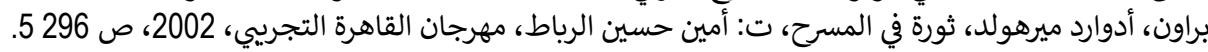

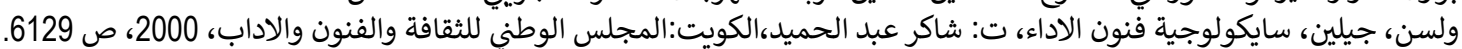

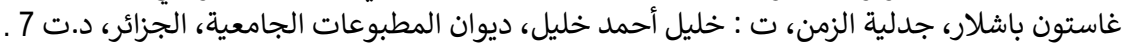

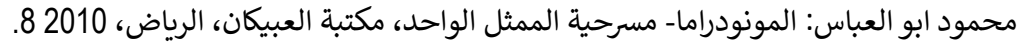

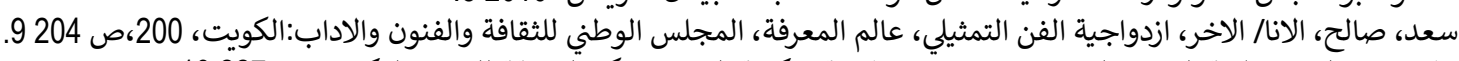

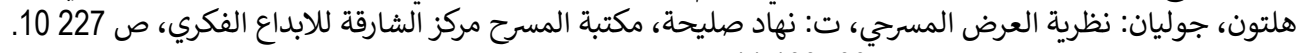

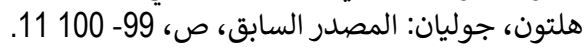

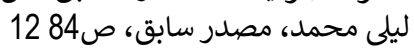
سفيلد، ان اوبر، مدرسه المتفرج، ص صد 26513 